\title{
«ET NUESTRO SEÑOR DIOS [...] FIZO COMMO EL BUEN AMIGO»: L'ESEMPIO XLVIII DEL CONDE LUCANOR E I SUOI PARALLELI (UNA RILETTURA)
}

\author{
Salvatore LuONGo \\ Università di Napoli "l'Orientale" \\ sluongo@unior.it
}

1. Il nucleo narrativo del capitolo XLVIII del Conde Lucanor $(C L)^{1}$, che affronta il tema della fede amicale ${ }^{2}$, è il risultato, come noto, di un complesso montaggio intertestuale. Ne costituisce la base il primo (De dimidio amico) dei due distinti racconti offerti in proposito dalla Disciplina clericalis (ca. 1110; il secondo, De integro amico, è dedicato all'amicizia completa) del giudeoconverso Pedro Alfonso. Da questo tipo ${ }^{3}$, di sicura matrice orientale,

\footnotetext{
${ }^{1} \mathrm{Ai}$ contributi ad esso dedicati cui si farà riferimento nel corso dell'argomentazione vanno aggiunti almeno: Archer Taylor, «An Old Friend is the Best Friend», in Romance Philology, 9 (1955-1956), pp. 201-205; Juan Bautista Avalle-Arce, «Una tradición literaria: el cuento de los dos amigos», in Nueva Revista de Filología Hipánica, 9 (1957), pp. 1-35; Kenneth R. Scholberg, «A Half-Friend and a Friend and a Half», in Bulletin of Hispanic Studies, 35 (1958), pp. 187-198; Salvatore Battaglia, «Dall'esempio alla novella», in Filologia Romanza, 7 (1960), pp. 21-84 (poi in Id., La coscienza letteraria del Medioevo, Napoli, Liguori, 1965, pp. 487-548, che utilizzo); Reinaldo Ayerbe-Chaux, «El concepto de la amistad en la obra del Infante don Juan Manuel», in Boletín del Instituto Caro y Cuervo, 24 (1969), pp. 37-49; Daniel Devoto, Introducción al estudio de don Juan Manuel y en particular de «El conde Lucanor». Una bibliografia, Madrid, Castalia, 1972, pp. 454-459; Robert B. Tate, «Don Juan Manuel and his Sources: Ejemplos 48, 28, 1», in Studia Hispánica in honorem R. Lapesa, 3 voll., Madrid, Seminario Menéndez Pidal-Gredos, 1972, vol. I, pp. 549-561, alle pp. 549-554; Rameline E. Marsan, Itinéraire espagnol du conte médiéval (VIII-XV siècles), Paris, Klincksieck, 1974, pp. 489-492; John E. Keller, «Another Look at Exemplo 48 in El Conde Lucanor», in La Córonica, 13 (1984-1985), pp. 1-9; Eric M. Furr e Connie L. Scarborough, «Reconciling the Secular and the Spiritual in Juan Manuel's Exemplo 48: Patronio's Ironic Application of the Half/Whole-Friend Tale», in Estudios alfonsinos y otros escritos en homenaje a John Esten Keller y a Anibal A. Biglieri, a cura di N. Toscano Liria, New York, National Hispanic Fundation for the Humanities, 1991, pp. 60-69.

${ }^{2} \mathrm{La}$ «prova degli amici» è repertoriata sia da Frederick C. Tubach, «Index Exemplorum». A Handbook of Medieval Religious Tales, Helsingfors, Akademia Scientiarum Fennica, 1969, n. 2216, che da John E. Keller, Motif-Index of Medieval Spanish Exempla, Knoxville (Tennessee), University Press of Tennesse, 1949; entrambi rinviano al tipo 893 e al motivo H 1158.1 della classificazione Aarne-Thompson.

${ }^{3} \mathrm{Su}$ di esso e le sue testualizzazioni ragguagliano Victor Ch. Chauvin, Bibliographie des ouvrages arabes ou relatifs aux arabes publiés dans l'Europe Chrétienne de 1810 à 1885, 12 voll., Liège, H.
} 
che conosce anche le rielaborazioni dei Castigos y documentos del rey don Sancho (sec. XIII ex.; CDS) e del Libro del caballero Zifar (sec. XIV in.; Z), don Juan Manuel desume i due attanti principali (un giovane e suo padre, che desidera sapere quanti amici egli abbia), la modalità della prova che l'anziano genitore, incredulo alla risposta del figlio, gli consiglia di porre in atto (uccidere un animale, metterlo in un sacco, recarsi dai suoi sedicenti amici, lasciar loro credere che nel sacco è nascosto un uomo da lui assassinato e chiedere aiuto per occultarlo), il risultato negativo della verifica (il figlio constata che nessuno è disposto ad aiutarlo), l'invito del padre a rivolgersi a un suo mezzo amico, l'ausilio prontamente prestato da costui, il quale, scavata una fossa, vi seppellisce il sacco con il suo compromettente contenuto ${ }^{5}$.

Oltre che per qualche dettaglio secondario (i cento presunti amici del figlio diventano dieci, il vitello ucciso è sostituito, in consonanza con il Zifar, da un maiale, forse prova dell'allontanamento dalle culture che ne proibivano il

Vaillant-Carmanne, 1892-1922, vol. IX, pp. 15-16; Gédéon Huet, «La parabole des faux amis», in Romania, 33 (1904), pp. 87-91 e 303-305; Haim Schwarzbaum, «International Folklore Motifs in Petrus Alfonsi's Disciplina Clericalis», in Sefarad, 21 (1961), pp. 267-299, alle pp. 283-288; Yolando Pino Saavedra, «Exemplum de dimidio amico. De la Disciplina Clericalis a la tradición oral chileno-argentina», in Lengua, Literatura, Folklore. Estudios dedicados a Rodolfo Oroz, a cura di G. Carillo Herrera, Santiago, Universidad de Chile, 1967, pp. 407-418; Otto Spies, "Arabicshe Stoffe in der Disciplina Clericalis», in Rheinisches Jahrbuch für Volkskunde, 21 (1973), pp. 170-199, alle pp. 171-177; Marsan, Itinéraire espagnol..., op. cit., pp. 468-495; Jürgen Stohlmann, «Orient Motive in der lateinischen Exempla-Literatur des 12. und 13. Jahrhunderts», in Orientalische Kultur und europäische Mittelalter, a cura di A. Zimmermann, I. Craemer-Ruegenberg, G. Vuillemin-Diem, Berlin-New York, de Gruyter, 1985, pp. 123-150; Barry Taylor, «Old Spanish Wisdom Texts: Some Relationships», in La Corónica, 14 (1985-1986), pp. 71-85; Id., «The Tale of the Half Friend (Aarne-Thompson 893) in some Hispanic Witnesses», in Historicist Essays on Hispano-Medieval Narrative in Memory of Roger M. Walker, a cura di B. Taylor e G. West, London, Maney Publishing, 2005, pp. 408-418; María Jesús Lacarra, «Ecos de la Disciplina en la tradición hispánica medieval», in Estudios sobre Pedro Alfonso de Huesca, coord. M. J. Lacarra, Huesca, Instituto de Estudios Altoaragoneses, 1996, pp. 275-289; Id., «"El medio amigo" (AT 893): la singularidad de las versiones hispánicas medievales a la luz de la tradición oral», in Tipología de las formas narrativas breves románicas medievales (III), a cura di M. J. Lacarra e J. M. Cacho Blecua, Zaragoza, Universidad de Zaragoza, 2004, pp. 267-292; Cristina González, «El cuento del medio amigo y la articulación onírica del Zifar», in Revista de Literatura Medieval, 14 (2002), pp. 53-62; Gaetano Lalomia, «I complessi percorsi del racconto del "medio amigo" nella Castiglia medievale», in Testi, generi e tradizioni della Romània medievale, Atti del VI Congresso della Società Italiana di Filologia Romanza (Pisa, 28-30 settembre 2000), a cura di F. Cigni e M.P. Betti, 2 voll., Pisa, Pacini 2002 [= Studi Mediolatini e Volgari, 47], vol. II, pp. 79-95; Lia Vozzo, «L'exemplum del "medio amigo" nel Libro del caballero Zifar», in Autour du XV siècle. Journées en l'honneur d'Alberto Varvaro, Liège, 10-11 Mai 2004, a cura di P. Moreno e G. Palumbo, Genève, Droz, 2008, pp. 248-257.

${ }^{4}$ Queste due versioni del racconto sono sottoposte a una accurata analisi comparativa con quella manuelina da A. Ruffinatto, «Il mondo possibile di Lucanor e di Patronio», postfazione a don Juan Manuel, Le novelle del "Conde Lucanor», a cura di A. Ruffinatto, trad. it. di Sandro Orlando, Milano, Bompiani, 1985, pp. 193-242 (poi nel suo Semiotica ispanica. Cinque esercizi, Alessandria, Edizioni dell'Orso, 1985, pp. 33-73), alle pp. 208-221.

${ }^{5}$ Per il testo della Disciplina clericalis rinvio all'ed. a cura di María Jesús Lacarra, trad. sp. di Esperanza Ducay, Zaragoza, Guara, 1980. 
consumo), il racconto manuelino si differenzia da quello di partenza per una notevole amplificazione discorsiva e per l'introduzione di una modifica di sostanza che avrà un ruolo decisivo nell'ulteriore svolgimento della trama ${ }^{6}$. Come gli altri interventi di cui si dirà, tanto la prima quanto la seconda risultano funzionali alla coerenza linguistica, strutturale e semantica dell'insieme, a conferma di quella stretta e dialettica interrelazione, ben messa in evidenza, tra gli altri, da Alberto Varvaro ${ }^{7}$, Aldo Ruffinatto ${ }^{8}$ e Fernando Gómez Redondo $^{9}$, fra parte narrativa e parte didattica-interpretativa che caratterizza gli enxiemplos del Conde Lucanor.

Anzitutto, di nuovo in analogia con la versione tramandata dal Zifar, don Juan esplicita la relazione docente-discente che già nella Disciplina clericalis si sovrapponeva implicitamente a quella padre-figlio. L'«ome bueno» del romanzo

era muy rico e avia vn fijo que queria muy bien, e dauale de lo suyo que despendiese, quanto el queria, e castigole que sobre todas las cosas e costunbres, que apresiese e punase en ganar amigos, ca esta era la mejor ganançia que podria fazer [...]. E el fijo le dixo que lo faria asi e que trabajaria de ganar amigos quanto el mas podiese.

En con el algo quel daua el padre conbidaua e despendia e daua de lo suyo granadamente, de guisa que non auia ninguno en la çibdat onde el era, mas aconpañado que el. E a cabo de dies años, preguntole el padre quantos amigos auie ganados, e el le dixo que más de çiento $(Z \text { p. } 81)^{10}$.

Allo stesso modo, il padre del Conde Lucanor intende impartire al giovane una lezione sull'amicizia, ragion per cui

entre las otras cosas quel mandava et le consejava, dizíal sienpre que puñasse en aver muchos amigos et buenos $(C L \text { p. 196 })^{11}$.

\footnotetext{
${ }^{6}$ Ragguaglia sia sull'una che sull'altra Ayerbe-Chaux, «El conde Lucanor». Materia tradicional y originalidad creadora, Madrid, Porrúa Turanzas, 1975, pp. 161-169.

${ }^{7}$ «La cornice del Conde Lucanor», in Studi di Letteratura Spagnola, 1 (1964), pp. 187-195 (poi ristampato in Id., Identità linguistiche e letterarie nell'Europa romanza, Roma, Salerno Editrice, 2004, pp. 515-524, da cui cito).

8 «Il mondo possibile...», art. cit.

${ }^{9}$ Historia de la prosa castellana, I. La creación del discurso prosístico: el entramado cortesano, Madrid, Cátedra, 1998, pp. 1156 e sgg.

${ }^{10}$ Utilizzo l'ed. a cura di Cristina González, Libro del caballero Zifar, Madrid, Cátedra, 1998.

${ }^{11}$ Traggo tutte le citazioni dall'ed. a cura di Guillermo Serés, Don Juan Manuel, El Conde Lucanor, con un estudio preliminar de Germán Orduna, Barcelona, Galaxia Gutenberg-Círculo de Lectores, 2006.
} 
Il figlio obbedisce, procurando di

aconpañarse et [...] partir de lo que avía con muchos omnes por tal de los aver por amigos (ibidem),

finché un giorno il genitore non decide di accertare se l'ordine è stato eseguito e con quale esito, per istruirlo sulla rarità degli «amigos verdaderos»:

Un día, estando aquel mancebo con su padre, preguntól si avía fecho lo quel mandara et si avía ganado muchos amigos. Et el fijo díjole que sí, que avía muchos (ibidem).

In questo modo il pattern del rapporto Patronio-Lucanor presente nella cornice si riflette all'interno della narrazione: come cioè in altri casi, Patronio ammaestra Lucanor servendosi di un esempio che mette in scena il medesimo ammaestramento: ${ }^{12}$

In secondo luogo, i supposti compagni del figlio gli assicurano

que farían por él todo cuantol cunpliesse et que aventurarían por él los cuerpos et cuanto en el mundo oviessen cuandol fuesse mester (ibidem),

e lo stesso giovane, interrogato dal padre, si dichiara certo che almeno dieci tra essi

por miedo de muerte nin de ningún recelo $[\ldots]$ nunca le errarién por quexa nin por mengua nin por ocasión quel acaesciesse (ibidem).

Nel rifiutare il loro aiuto i falsi amici accampano tutti la stessa giustificazione:

todos le dixieron que en otras cosas le ayudarién, mas que en esto, porque podrían perder los cuerpos et lo que avían, que non se atreverían a le ayudar et que, por amor de Dios, que guardasse que non sopiessen ningunos que avía ydo a sus casas ( $C L$ p. 197).

Ragione cui allude in verità anche il mezzo amico, che nondimeno lo soccorre:

${ }^{12}$ «La presenza del momento didattico interno al racconto non è, come potrebbe pensarsi, caratteristica eccezionale dell'esempio I, in quanto anche altre volte la somiglianza fra la situazione del conte e quella dei personaggi dei racconti sarà tale che il consiglio dato da uno di essi risulterà identico a quello dato poi da Patronio al conte» (A. Varvaro, «La cornice...», art. cit., p. 518). 
«ET NUESTRO SEÑOR Dios [...] Fizo COMMO EL BUEN AMIGO»: L'eSEMPiO XLVIII...

Cuando el medio amigo de su padre aquello vio, díxol que con él non avía amor nin afazimiento por que se deviesse tanto aventurar, mas que por el amor que avía con su padre que gelo encubriría (CL pp. 197-198).

Si tratta di riprese pressoché letterali delle parole con cui nella prima parte della cornice Lucanor sollecita il parere di Patronio:

Patronio, segunt el mío cuydar, yo he muchos amigos que me dan a entender que por miedo de perder los cuerpos nin lo que han que non dexarían de fazer lo que me cunpliesse, que por cosa del mundo que pudiesse acaescer non se parterían de mí. Et por el buen entendimiento que vós avedes, ruégovos que me digades en qué manera podré saber si estos mis amigos farían por mí tanto commo dizen (CL pp. 195-196).

Richiesta che genera il racconto del consigliere, il quale, prima di passare a narrarlo, anticipa così la propria opinione:

- Señor conde Lucanor -dixo Patronio-, los buenos amigos son la mejor cosa del mundo. Et bien cred que cuando viene grand mester et la grand quexa, que falla omne muy menos de cuantos cuyda; et otrosí, cuando el mester non es grande, es grave de provar cuál sería amigo verdadero cuando la priessa veniesse. Pero para que vós podades saber cuál es el amigo verdadero, plazerme ýa que sopiéssedes lo que contesció a un omne bueno con un su fijo que dizía que avía muchos amigos (CL p. 196),

per poi ribadirla al termine della narrazione, insistendo su termini analoghi (vedi citazione infra).

Dopo aver negato al giovane ogni concreto sostegno, alcuni di coloro che egli riteneva amici si prodigano tuttavia in promesse, di pregare per lui o di accompagnarlo al patibolo prima e alla sepoltura poi:

Pero destos amigos, algunos le dixieron que non se atreverían a fazerle otra ayuda, mas que yrían rogar por él; et otros le dixieron que cuando le levassen a la muerte, que non lo desanpararían fasta que oviessen conplido en él la justicia et quel farían onra al su enterramiento ( $C L$ p. 197).

L'articolazione, rispetto alla fonte, della risposta dei presunti amici, prepara la lettura tipologica del racconto che Patronio proporrà nella seconda parte del suo commento, sulla quale mi soffermerò più avanti.

Ad identico fine risponde anche l'inserimento della variante sostanziale cui si accennava sopra: laddove nella Disciplina clericalis, seguita anche 
dalle versioni dei Castigos e del Zifar, il padre, in opposizione alla vanagloria del figlio, confessava di non essere riuscito in tutta la sua lunga vita ad avere più di mezzo amico, nel racconto di Patronio l'anziano genitore dichiara invece di possedere non più di un amico e mezzo:

Cuando el padre esto oyó, díxol que se marabillava ende mucho porque en tan poco tiempo pudiera aver tantos amigos et tales, ca él, que era mucho anciano, nunca en toda su vida pudiera aver más de un amigo et medio ( $C L$ p. 196),

e consiglia al figlio di rivolgersi a entrambi:

Estonce le dixo que él non avía más de un amigo et medio, et que los fuesse provar (CL p. 197).

Con l'accenno non ad un unico personaggio, deputato a incarnare una delle forme della fedeltà amicale, bensì a due distinti attori, diversamente qualificati («amigo» e «medio amigo»), don Juan Manuel crea le premesse da un lato per un inedito sviluppo della narrazione con una serie di altre importanti funzioni, assenti nel testo base, che gli consentirà di fondere il tema dell'amicizia a metà con quello dell'amicizia intera ${ }^{13}$, dall'altro per completare appunto l'interpretazione figurale cui il racconto di Pedro Alfonso e i suoi derivati solo parzialmente si prestavano.

Ma procediamo. Come accennato, il giovane si reca dunque dal mezzo amico del padre, il quale, ascoltatolo, si mette a sua completa disposizione, provvedendo alla sepoltura del sacco. A partire da questo punto, la storia offerta da Patronio abbandona il percorso diegetico tracciato dalla Disciplina clericalis per seguire quello disegnato dalla versione $\beta$ dei Castigos $^{14}$ (fin qui sostanzialmente coincidente ${ }^{15}$; la versione $\alpha$ continua invece a ricalcare fedelmente l'intreccio del testo latino $)^{16}$, della quale aveva già accolto una

\footnotetext{
${ }^{13}$ M. a J. Lacarra, «“El medio amigo”...», art. cit., p. 284, n. 23, segnala che «También en una versión árabe de la primera mitad del siglo Xv se fusionan las dos historias de la Disciplina clericalis al hacer que el padre tenga dos amigos, un medio amigo y uno íntegro»; in questo caso, tuttavia, «sólo desarrolla una única prueba. Con buenas palabras, el medio amigo les niega su ayuda al padre y al hijo y tienen que recurrir al amigo entero. Éste no sólo se compromete a enterrar el saco sino que les ofrece todos sus bienes, su familia, sus casas y hasta su propia vida, si hiciera falta».

${ }^{14}$ Che cito dall'ed. a cura di Hugo Ó. Bizzarri, Castigos del rey don Sancho IV, Frankfurt-Madrid, Vervuert-Iberoamericana, 2001.

${ }^{15} \mathrm{Vi}$ risulta però trasferito «nello spazio e nel tempo $i l$ momento della rivelazione o agnizione, $[\ldots]$ mediante l'interpolazione di altri segmenti narrativi»: il mezzo amico esce «di casa, senza peraltro notare nessuna agitazione particolare in città come conseguenza del grave fatto che lui ritiene accaduto, e si reca dal padre in veste di informatore»; «il padre lo ringrazia e lo prega di rimandare a casa suo figlio» (A. Ruffinatto, «Il mondo possibile...», art. cit., p. 210).

${ }^{16}$ Per le divergenze tra i due rami della tradizione si veda María Jesús Lacarra, «Los exempla en 
variante (il luogo in cui viene sotterrata la finta salma è un orto di cavoli) ${ }^{17}$ che troverà ora una significativa eco. Nel cuento del re don Sancho, tornato il figlio a casa, il padre organizza un sontuoso banchetto, al quale invita sia gli amici infedeli del giovane che il suo mezzo amico; nel corso del pranzo l'anziano genitore ordina al «moço» di trovare un pretesto per attaccare lite con il suo salvatore e di colpirlo con «vna bofetada en las baruas»; dopo aver invano protestato, il figlio è costretto ad eseguire le disposizioni paterne; il mezzo amico tuttavia non reagisce, e alludendo in modo sibillino all'orto della sepoltura lascia intendere che non rivelerà il segreto che ormai li vincola:

El buen omne mando luego conbidar a todos aquellos amigos de su fijo que auia prouado commo ya oystes. E esso mesmo al su medio amigo para el domingo primero que todos veniessen a comer con el a su posada. E el buen fijo fizolo assy commo su padre le mando. Conbidados todos a la yantar de muchas aues e de muchas buenas uiandas e con muchos juglares e con mucho plazer llamo el omne a su fijo e sobre todo a yantar mandole que so pena de la su bendiçion que se llegasse a aquel su medio amigo e que le diesse vna bofetada en las baruas ante todos los que y estauan. E el buen fijo commo esto oyesse fue muy triste e dixo: Padre, non quiera Dios que yo faga tal cosa a quien tan grant amorio me mostro. Torno el padre e dixo: Yo te maldire e non auras parte en mas bienes si lo non fesieres. El buen fijo referto a tanto que començo a entresteçer e a llorar deziendo que ante sabria morir que tal cosa fazer. E el padre tomo tan grande enojo e tanta de sanna a que lo mandaua que se fuesse luego fuera de su casa. E commo todos estouiessen en su plazer dixieron al moço: Fijo, fazet lo que vuestro padre vos manda. Estonçes el moço con mucha uerguença e temor llegosse al omne bueno e diole vna palmada en el rostro. E commo el omne bueno se uido assi ferir con omildoso gesto e paçiente palabra dixo: Avnque me des otra a tuerto e sin derecho nunca se descobriran las uerças del huerto. A estas palabras fueron todos muy marauillados por que non podieron entender por que se dezian $(C D S$, versione $\beta$, pp. 258-259).

los Castigos de Sancho IV: divergencias en la trasmisión manuscrita», in La literatura en la época de Sancho IV, Actas del Congreso Internacional (Alcalá de Henares, 21-24 de febrero de 1994), a cura di C. Alvar e J. M. Lucía Megías, Alcalá de Henares, Servicio de Publicaciones de la Universidad de Alcalá, 1996, pp. 201-212.

${ }^{17}$ Così il $C L$ p. 198: «Entonce tomó el saco con el puerco a cuestas, cuydando que era omne, et levólo a una su huerta et enterrólo en un sulco de coles, et puso las coles en el surco assí como ante estavan»; ed ecco il parallelo dei $C D S$, versione $\beta$, p. 258: «E fueronsse entramos a vna huerta quel buen omne tenia en su casa e arranco en vn saco muchas de las coles e tomo vna a cada e fizo grant fuessa e enterro y el saco assi commo estaua e tornose a plantar las coles ençima en manera que non pareçia que y estodiesse otra cosa alguna». 
Ed ecco, molto più succinto e con la sostituzione del banchetto con un'assemblea, il parallelo manuelino:

El padre le mandó que otro día, cuando estudiessen en concejo, que sobre cualquier razón que despartiessen, que començasse a porfiar con aquel su medio amigo et, sobre la porfía, quel diesse una puñada en el rostro, la mayor que pudiesse. El mancebo fizo lo quel mandó su padre. Et cuando gela dio, catól el omne bueno et díxol:

-A buena fe, fijo, mal feziste; mas dígote que por este nin por otro mayor tuerto non descubriré las coles del huerto ( $C L$ p. 198).

Ma laddove nei Castigos $\beta$ la prova supplementare cui viene sottoposto il mezzo amico è una prova qualificante, funzionale cioè alla sua promozione ad «amigo conplido e uerdadero»:

E mas agora [chi parla è il padre] mandele que por galardon de lo que auia fecho que le diesse aquella bofetada en sus baruas por uer si era amigo uerdadero. E por quanto en plaça ante todos vosotros resçibio aquesta injuria e non reclamo nin descobrio lo passado, yo lo tengo conplido e uerdadero $(C D S$, versione $\beta$, p. 259),

la ragione che motiva l'interpolazione del nuovo test (che consiste in un'offesa perdonata) e insieme la sua riduzione all'essenziale nella narrazione di $\mathrm{Pa}$ tronio è da ricercare ancora una volta, lo si vedrà, nella sezione commentativa dell'enxiemplo di cui essa forma parte, allorché, per bocca del consigliere, don Juan ne offrirà una peculiare interpretazione allegorica, istituendo una serie di precise corrispondenze tra singoli e concreti elementi del racconto (littera) e significato (sensus) loro assegnato.

2. Il seguito del racconto del consigliere non trova invece ovviamente riscontro né nel racconto inaugurale della Disciplina clericalis (che si conclude con il ringraziamento e la rivelazione al mezzo amico del reale contenuto del sacco da parte del figlio, il quale, tornato dal padre e ragguagliatolo sull'accaduto, ne riceve un ammaestramento in forma di sentenza sull'amicizia certa $)^{18}$ né nei suoi continuatori. Promosso il mezzo amico ad amico intero, esaurita cioè l'esemplificazione dei possibili comportamenti amicali, i Castigos omettono un secondo racconto affine a quello complementare (De

\footnotetext{
${ }^{18}$ «Cum autem ille omnia parata videret, rem prout erat disseruit gratias agens. Deinde patri retulit quae fecerat. Pater vero ait: "Pro tali amico dicit philosophus: Hic est vere amicus qui te adiuvat, cum saeculum tibi deficit"».
} 
integro amico) che Pedro Alfonso immediatamente fa seguire al primo. Il Zifar presenta invece l'innesto di un'ampia integrazione, preparata da una serie di precedenti interventi, sulla quale varrà la pena di trattenersi brevemente. Il nostro racconto è il primo degli exempla che interrompono il filo della trama principale del romanzo. A causa della sua malasorte (ogni dieci giorni gli muore il cavallo) l'eroe eponimo è stato allontanato dal servizio; avvilito, egli manifesta ad alta voce il desiderio di partire per realizzare un segreto proposito: riconquistare il regno perduto a causa del peccato dai suoi avi; la moglie Grima, che ha ascoltato, lo convince a condividere con lei tanto lo sconforto quanto le intenzioni; Zifar ammette che poter partecipare ad un amico le proprie preoccupazioni gli sarebbe di grande sollievo, e tuttavia, osserva, sull'amicizia è facile ingannarsi, come dimostra, appunto, l'«exemplo» del «medio amigo». Fin dal suo avvio il racconto presenta una serie di significative varianti, foriere di successivi sviluppi: il giovane attacca briga con un coetaneo di più elevata condizione, il quale si mette alla sua ricerca per vendicarsi; il padre allora lo nasconde in un luogo sicuro e, senza che egli lo sappia, compone il contrasto; infine, sempre a insaputa del figlio, prepara il sacco con il maiale e, al suo ritorno, gli lascia credere che esso contiene il cadavere fatto a pezzi del suo avversario. Ciò determina la precondizione per l'inserzione, subito dopo la sequenza in cui il giovane ottiene l'aiuto del mezzo amico, di un nuovo episodio, il quale parrebbe allontanare la narrazione dal fine didascalico che la presiede. Dopo aver ammonito il figlio sulla necessità di saper distinguere i veri dai falsi amici, l'anziano genitore lo rimanda dal suo mezzo amico per chiedergli di cucinare quanto è contenuto nel sacco, di modo che tutti e tre se ne possano cibare la sera seguente ${ }^{19}$. Il giovane, turbato, protesta, ma poi obbedisce. Il mezzo amico comprende immediatamente la burla, ne ride e si presta al gioco. Sedutisi a tavola, il «moço», sia pure riluttante, mangia quella che crede essere carne umana e, trovandola squisita, propone di uccidere anche il compagno del suo nemico per poterne gustare ancora. Temendo che il figlio possa pericolosamente scivolare verso l'antropofagia, il padre gli svela l'inganno e lo ammaestra prima, di nuovo, sulla scelta degli amici e poi sull'illiceità del cannibalismo. Il giovane dichiara di aver appreso la lezione e assicura che d'ora in avanti si guarderà dagli «amigos de enfinta». Come ha convincentemente argomentato Lia $\mathrm{Vozzo}^{20}$, questa apparente deviazione dal tema principale assolve invece a una precisa

\footnotetext{
${ }^{19}$ Per il motivo dell'antropofagia nella tradizione iberica, dove per lo più è sviluppato in chiave comica, rinvio a Harriet Goldberg, «Cannibalism in Iberian Narrative: The Dark Side of Gastronomy», in Bulletin of Hispanic Studies, 74 (1997), pp. 107-122.

${ }^{20}$ «L'exemplum del "medio amigo"...», art. cit. (citazione a p. 256).
} 
e suppletiva funzione. «Per l'autore del Zifar», difatti, «il buon amico deve essere anzitutto un buon consigliere $»^{21}$; lo conferma il dialogo che prelude all'inserimento dell'exemplum, nel corso del quale Grima, invitando il marito a «partir el cuydado con sus amigos», adduce la seguente motivazione:

«[...] E non se deue ome enfiuzar en su buen entendimiento solo, commoquier que Dios le de buen seso natural; ca do ay buen seso ay otro mejor. E porende todo ome que alguna grant cosa quiere començar e fazer, deue lo fazer con consejo de aquellos de quien es seguro quel consejaran bien. E amigo», dixo ella, «esto vos oy dezir, quexandovos, que queriades yr con vuestro fecho adelante e non dexar vuestro proposito començado, e porque se que vos sodes ome de grant coraçon e de grant fecho, tengo que este vuestro proposito es sobre alta cosa e grande, a que segunt mio cuydar deuedes auer vuestro consejo» $(Z$ p. 80).

Il racconto si propone dunque di illustrare la necessità di scegliere un consigliere adeguato oltre che leale ${ }^{22}$, diffidando da quelli non dotati di sufficiente senno («buen entendimiento», «buen seso natural»). Ed in effetti nella versione del Zifar a essere messo alla prova è soprattutto il figlio: in primo luogo il padre ne saggia la capacità di mettere a frutto il denaro e il consiglio che gli ha dato; poi sottopone a verifica l'affermazione che ciascuno dei suoi cento amici sarebbe disposto a correre qualsiasi rischio per lui; infine, mediante la messinscena del banchetto (pseudo)cannibalesco, procede a testarne la resistenza all'impulso (la voluntad) per i piaceri proibiti (nello specifico: cibarsi di carne, squisita sì, ma umana) esercitando appunto l'entendimiento; allarmato dalla reazione del ragazzo, provvede dunque prontamente a correggerne l'erronea inclinazione, giacché

sy este moço durase en esta imaginaçion, que seria muy cruo e que lo non podrian ende partir; ca las cosas que ome ymagina mientra moço es, mayormente aquellas cosas en que toma sabor, tarde o nunca se puede dellas partir (Z p. 84).

${ }^{21}$ Sull'equivalenza tra «buen amigo» e «buen consejero» in altri testi castigliani medievali, si veda Hugo Ó. Bizzarri, Diccionario paremiológico e ideológico de la edad media (Castilla, siglo XIII), Buenos Aires, Secrit, 2000.

${ }^{22} \mathrm{Nel}$ Medioevo, l'insistenza sull'esigenza di chiedere il consiglio di altri prima di una scelta importante «costituisce in un certo senso il prologo di ogni discorso morale sul consilium: è infatti dalla necessità del consiglio che prende le mosse il discorso sulle condizioni e le regole del buon consiglio» (Carla Casagrande, "Virtù della prudenza e dono del consiglio», in Consilium. Teorie e pratiche del consigliare nella cultura medievale, a cura di C. Casagrande, C. Crescini e S. Vecchio, Firenze, SISMEL-Edizioni del Galluzzo, 2004, pp. 1-14, a p. 1). 
Il fallimento della prova del pasto dimostra tuttavia «come i giovani non possano essere considerati buoni consiglieri, dal momento che la ricerca del piacere può portarli fino al punto di dimenticare la stessa "ragione naturale" ${ }^{23}$, che è all'origine di ogni sapere. Esaurito il discorso sul mezzo amico, il Zifar, in sintonia con la Disciplina clericalis, affida a un secondo racconto, narrato, su sollecitazione del figlio («Dezitme sy podre prouar e conosçer qual es el amigo entero», $Z$ p. 85), dallo stesso padre personaggio della prima narrazione, volto ad illustrare l'amicizia perfetta.

Torniamo al Conde Lucanor. Come si diceva, l'accenno a due diversi personaggi, l'uno con la qualifica di «medio amigo», l'altro con la qualifica di «amigo», prelude alla trattazione, all'interno della medesima narrazione, di entrambi i modelli amicali. Uscito di scena il primo, fa infatti il suo ingresso, «inserito nello stesso ambiente» e «messo a contatto con gli stessi "attori"» della parte iniziale del racconto, il secondo, sicché «la sua storia si snoda lungo il percorso della precedente, a guisa di continuazione $\rangle^{24}$. Juan Manuel sembrerebbe pertanto completamente prescindere dal De integro amico presente nella Disciplina clericalis e dalla sua rielaborazione in castigliano tramandata dal Zifar, exemplum ovviamente accomunato al De dimidio amico dall' argomento, ma da esso assolutamente distinto e separato ${ }^{25}$. Questo il suo intreccio nella testualizzazione di Pedro Alfonso:

Due mercanti, l'uno egiziano e l'altro di Bagdad, sono in ottimi rapporti commerciali. Un giorno il secondo viene accolto con festeggiamenti e trattato con tutti gli onori in casa del primo. L'ospite però si ammala, perché innamorato della promessa sposa dell'egiziano, e questi, in segno di amicizia, rinuncia alla donna, cedendogliela. Anni più tardi il collega di Bagdad avrà l'occasione di restituirgli il favore. L'egiziano, rovinato e disperato, si mette in viaggio verso Bagdad alla sua ricerca. Giunto in città di notte, trova riparo in un tempio. Nelle vicinanze si verifica un delitto, del quale, spinto dalla volontà di morire, il mercante egiziano si attribuisce falsamente la colpa e viene condannato a morte. Lungo la strada che lo conduce al patibolo incontra ed è

\footnotetext{
${ }^{23}$ L.Vozzo, «L'exemplum del "medio amigo"...», art. cit., p. 262.

${ }^{24}$ A. Ruffinatto, «Il mondo possibile...», art. cit., p. 215.

${ }^{25}$ Nutrita anche in questo caso la bibliografia: si vedano almeno Chauvin, Bibliographie des ouvrages arabes..., op. cit., pp. 16-17; Louis Sorieri, Boccaccio's Story of Tito e Gisippo in European Literature, New York, Institut of French Studies, 1937; S. Battaglia, «Dall'esempio...», art. cit.; H. Schwarzbaum, «International Folklore Motifs...», art. cit., pp. 289-294; O. Spies, «Arabishe Stoffe...», art. cit., pp. 176-177; R. Marsan, Itinéraire espagnol..., op. cit., pp. 468-495; Bernard Darbord, «Variations autour du thème de l'amitié», in Cahiers de Linguistique Hispanique Médiévale, 22 (1998-1999), pp. 119-129, e Id., «Le thème des deux amis, dans la Disciplina clericalis et quelques autres textes», in Romania una et diversa. Philologische Studien für Theodor Berchem zum 65. Geburtstag, a cura di M. Guille e R. Kiesler, 2 voll., Tübingen, Narr, 2000, vol. II, pp. 515-522.
} 
riconosciuto dall'amico, il quale non esita a prendere su di sé la responsabilità dell'omicidio. A questo punto il vero assassino, che assiste alla scena, si fa avanti e confessa. I tre sono affidati alla giustizia del re, che, accertata la verità, li assolve tutti. Il mercante di Bagdad dona dunque all'amico egiziano la metà dei suoi beni e quest'ultimo può fare ritorno in patria.

Tuttavia nella seconda metà della trama che abbiamo riassunto, sono facilmente riconoscibili alcune delle fondamentali funzioni narrative che strutturano l'ultima parte del racconto di Patronio:

verificarsi di un reale assassinio:

Acaesció por ventura que en aquel tiempo avían muerto un omne en aquella villa, et non podían saber quién lo matara (CL p. 198);

coinvolgimento di un innocente nel fatto di sangue:

Et porque algunos vieron que aquel mancebo avía ydo con aquel saco a cuestas muchas veces de noche, tovieron que él lo avía muerto (ibidem);

giudizio e sua condanna alla pena capitale:

¿Qué vos yré alongando? El mancebo fue jubgado que lo matassen (ibidem);

sacrificio dell'amico intero, sia pure con una variante di notevole rilievo (non addossa la responsabilità del delitto a sé, ma al suo unico figlio):

Et el amigo de su padre avía fecho cuanto pudiera por lo escapar. Desque vio que en ninguna manera non lo pudiera librar de muerte, dixo a los alcaldes que non quería levar pecado de aquel mancebo, que sopiessen que aquel mancebo non matara el omne, ma que lo matara un su fijo solo que él avía [...]. Et escapó de la muerte el fijo del omne bueno que era amigo de su padre (ibidem).

Siamo con ogni evidenza, lo ha perfettamente chiarito Aldo Ruffinatto ${ }^{26}$, dinanzi a un processo di condensazione del programma narrativo svolto dal De dimidio amico e, sia pure limitatamente ad alcune delle sue componenti diegetiche costitutive, del programma narrativo svolto dal De integro amico «in un solo programma articolato in due sottoprogrammi». Del tutto differente risulta però l'epilogo della vicenda, felice nella Disciplina clericalis,

${ }^{26}$ «Il mondo possibile...», art. cit., p. 214. 
«ET NUESTRO SEÑOR Dios [...] Fizo COMMO EL BUEN AMIGO»: L'eSEMPIO XLVIII...

tragico nel Conde Lucanor, per le solite ragioni, lo si vedrà tra un momento, interpretative:

Et fizo al fijo que lo cognosciesse, et el fijo otorgólo, et matáronlo (ibidem).

Questa crudele conclusione, rammenta Ruffinatto ${ }^{27}$, ha suscitato la reazione negativa di critici autorevoli, quali,

ad esempio, quella di Valbuena Prat che riscontra un grado elevato di assurdità e di crudeltà nella situazione limite, benché consequenziale alla trama, predisposta da don Juan Manuel: «Éste lleva la abnegación del buen amigo a un grado absurdo y cruel; aunque expresándose muy bien el interés y la pequeña intriga de la narración». Critica ripresa da Scholberg, il quale afferma che dal punto di vista umano la storia - così come la racconta don Juan Manuel - è inaccettabile, e rimarcata con toni ancor più veementi da $\mathrm{S}$. Battaglia: «ora l'amico 'medio' [Battaglia non si avvede dell'ingresso in scena di un nuovo attore] s'induce a incolpare il proprio figlio innocente al posto del presunto assassino, solo per celebrare la perfetta amicizia. A tale assurdità non si attentava Pietro Alfonso, e tanto meno il Boccaccio [...]. Quest'ultimo episodio sembra un'interpolazione, e si stenta ad attribuirne la paternità a Juan Manuel. La prova d'amicizia che qui si prospetta è paradossale e immorale, ed ha una esemplarità alla rovescia $)^{28}$.

Critiche, osserva ancora lo studioso italiano, che non hanno senso allorché si estende l'osservazione alla cornice, e in particolare all'esplicazione del racconto offerta da Patronio. A dire il vero Juan Manuel non è il solo a far riferimento all'estremo sacrificio della vita per dimostrare un'amicizia perfetta. Lo stesso Zifar, introducendo il cuento del «medio amigo», elenca la seguente tipologia:

$\mathrm{Ca}$ tres maneras son de amigos: los vnos de enfinta, e estos son los que non guardan a su amigo synon demientra pueden fazer su pro con el; los otros son medios, e estos son los que se paran por el amigo a peligro que non paresçe, mas es en dubda sy sera o non; e los otros son enteros, los que veen al oio la muerte o el grant peligro de su amigo e ponen se delante para tomar muerte por el, que el su amigo non muera nin resçiba daño $(Z$ p. 81$)$.

${ }^{27}$ Ibidem, pp. 216-217.

${ }^{28}$ I riferimenti sono rispettivamente a Ángel Valbuena Prat, Historia de la Literatura Española, I. Edad Media, $9^{a}$ edición ampliada y puesta al día por A. Prieto, Barcelona, Gili, 1981, p. 249; K. R. Scholberg, «A Half-friend...», art. cit., p. 192, e S. Battaglia, «Dall'esempio...», art. cit., pp. 502-503. 
Per restare ai testi castigliani (ma si pensi all'Historia septem sapientum o all'Ami et Amile), allorché nel Calila e Dimna il re (cap. IX) chiede un «enxenplo de los dos enemigos», il filosofo gli narra la storia «Del gato et del mur», all'interno della quale il topo classifica due tipi di amici:

Los amigos son en dos maneras: el uno es amigo puro, et el otro es el que faze amistad de otro en ora de cuita et de nesçesidad. Onde el puro amigo deve amar al amigo más que a sí mesmo et a sus parientes et a su aver, ca es leal por naturaleza. Et el otro, que se toma por ora de cuita, a las vezes dura su amor et a las vezes desfázese ${ }^{29}$.

Ma don Juan è ben consapevole della eccezionale e sovrumana abnegazione richiesta da siffatta forma di amicizia. L'ultimo capitolo del suo Libro enfini$d o^{30}$, il XXVI, è dedicato al tema dell'«amor», termine che egli utilizza per riferirsi all'amore per Dio, a quello paterno e filiale, ma anche all'amicizia ${ }^{31}$. Ammaestrando il figlio Fernando sull'argomento, gli raccomanda di provare la qualità dell'amore che gli altri nutrono nei suoi confronti, mettendoli alla prova, giacché esistono diverse «maneras de amor», elencandone quindici. Tra di esse compaiono l'«amor conplido» (al primo posto) e l'«amor verdadero» (al quarto), i due tipi rispettivamente incarnati, nel nostro esempio, dall'amico intero e dal mezzo amico. Quanto all' «amor verdadero», don Juan afferma:

amor verdadero es quando algun omne, por debdo sennalado o por buen talante, ama a otro et lo a prouado en grandes fechos et peligros, et fallo en el sienpre verdat et ayuda et buen consejo (p. 185).

Si tratta dunque dell'amore provato e sperimentato, rarissimo, del quale va fatto tesoro:

Quando tal amigo como este fallaredes, consejo vos quel amedes mucho et fiedes en·el, et fagades por el, si acaesçiere en·que, mas que el fizo por vos. Et gradesçed mucho a.Dios si uos diere tal amigo; ca digo vos que fasta aqui, maguer que he pasado çinqüenta annos, abes vos podria dezir que falle de tales amigos mas de vno, et non lo quiero nonbrar por non me perder con los

${ }^{29}$ Calila e Dimna, ed. a cura di Juan Manuel Cacho Blecua e María Jesús Lacarra, Madrid, Castalia, 1984, p. 270.

${ }^{30}$ Che cito dall'ed. a cura di José Manuel Blecua, don Juan Manuel, Obras completas, 2 voll., Madrid, Gredos, 1982-1983, vol. I.

${ }^{31} \mathrm{Si}$ veda Ian Macpherson, «Amor and Don Juan Manuel», in Hispanic Review, 39 (1971), pp. 167-182. 
«ET NUESTRo SEÑOR dios [...] Fizo COMMO El BUEN AMIGO»: L’eSEMPIO XLVIII...

otros. Mas digo vos que si mi ayuda oviese mester, que me doldria poco de aventurar por el el cuerpo et quanto oviese (ibidem).

L'«amor conplido» è invece definito in questo modo:

amor conplido es entre dos personas en tal manera, que lo que fuere pro de $\cdot 1 \mathrm{a}$ vna persona o lo quisiere, que lo quiera la otra tanto commo el, et que non cate en ello su pro, nin su danno; asi que avn que la cosa su danno sea, quel plega de coraçon de·la fazer, pues es pro et plaze a'su amigo [...]. Et a esto podria dezir alguno que esto non es amor, mas es locura del que asi ama. Et digo yo que non; ca si el amor fuese conplido de cada parte, non seria esto; ca si la persona que demandase lo «que» non fuese pro de su amigo amase de conplido amor, non quer $r$ ria que su amigo fiziese por el cosa que fuese su danno. Mas por que los amigos non pueden ser eguales en amar et en poder et en e $<$ n tendimiento, o en otras muchas cosas por que el amor seria egual, por esto vos digo que yo nunca vi fasta oy amor conplido (pp. 183-184).

L'amore intero richiede dunque una generosità estrema (amare più il prossimo che se stessi), sicché è una forma di amore superiore, irrealizzabile «entre los omnes». Non stupisce pertanto che, nel commentare il nostro racconto, Patronio impartisca a Lucanor una duplice lezione, la prima inerente i rapporti tra gli uomini nel mondo, la seconda concernente il rapporto dell'uomo con Dio, in perfetta sintonia, oltretutto, con il doppio obiettivo che il Conde Lucanor a più riprese addita ai suoi destinatari, dai Prologhi che lo introducono al conclusivo Libro de la doctrina: «aprovechamiento del cuerpo» e «salvamiento del alma». Già in una precedente occasione (la lunga chiosa al racconto del leone e del toro incorniciato nel capitolo XXII), il consigliere aveva avuto modo di istruire il conte sull'amicizia, nello specifico quando essa è minacciata dalla calunnia, asserendo che per riconoscere il sodale fidato, sul quale fare assegnamento come su di un «buen fijo» o un «buen hermano», dovrà considerare se «falló en él sienpre buenas obras et leales», e vigilare invece nei confronti di quegli «amigos que se aman por el tienpo o por la ventura o por el mester» ${ }^{32}$, pronto a cogliere «alguna señal cierta» che ne denunci la slealtà ( $C L$ pp. 92-93). In risposta al quesito di carattere generale («ruégovos

\footnotetext{
${ }^{32}$ Inevitabile, anche qui, il rinvio al cap. XXVI del Libro enfindo per le definizioni delle tre specie di amicizia: «amor de tienpo es quando vn omne ama a otro por que en aquel tienpo le cunple el su amor, et desque aquel tienpo es pasado, olbida de ligero lo que el otro por el fizo» (p. 187); «amor de·la ventura es quando vn omne ama a otro por quel va muy bien et la ventura es en su ayuda. Mas pues non le ama si non por la buena ventura, que asi la bentura se buelue, luego el amor es partido» (ibidem); "amor de mester es quando 〈vn〉 omne esta en tal mester que 1 〉 cunple mucho el ayuda de su amigo por que acabe aquel mester en que esta, o salga del asi commo cunple; et en quanto esta en aquel mester, muestral grant amor, et desque aquel fecho es acabado, vasse esfriando et alongando de su amor» (p. 186).
} 
que me digades en qué manera podré saber si estos mis amigos farían por mí tanto commo dizen», $C L$ p. 196) posto da Lucanor, al quale molti amici assicurano una fedeltà incondizionata, il precettore completa ora l'insegnamento con una serie di prescrizioni pratiche, applicabili appunto «en este mundo», che eleggono ancora una volta le «señalas ciertas», i comportamenti concreti, positivi o negativi, a fondamento:

Agora, señor conde Lucanor, vos he contado cómmo se pruevan los amigos, et tengo que este enxiemplo es bueno para saber en este mundo cuáles son los amigos, et que los deve provar ante que se meta en grant periglo por su fuza, et que sepa a cuánto se pararan por él sil fuere mester. Ca cierto seet que algunos son buenos amigos, mas muchos, et por aventura los más, son amigos de la ventura; que assí commo la ventura corre, assí son ellos amigos (CL pp. 198-199).

Dopodiché, mediante una formula introduttiva («Otrosí, este enxienplo se puede entender spiritualmente en esta manera», $C L$ p. 199) analoga a quelle che sogliono adoperare gli esegeti della Bibbia $^{33}$, Patronio trasferisce il proprio discorso dal piano referenziale-denotativo sul quale finora si è mosso a un piano anagogico-connotativo ${ }^{34}$, per offrire a Lucanor il secondo insegnamento ${ }^{35}$.

3. Il procedimento interpretativo adottato da Juan Manuel è affine (ma non identico $)^{36}$ a quello tipologico esercitato sugli eventi narrati dall'Antico

\footnotetext{
${ }^{33}$ Sterminata la bibliografia in proposito; si vedano almeno Beryl Smalley, Lo studio della Bibbia nel Medioevo [1952], trad. it., Bologna, Il Mulino, 1972; Henning Brinkmann, Mittelalterliche Hermeneutik, Tübingen, Niemeyer, 1980; Brian Stock, The Implications of Literacy. Written Language and Models of Interpretation in the Eleventh and Twelfth Centuries, Princeton (N. J.), Guilford-Princeton University Press, 1983, e Philippe Buc, L'ambigüité du Livre. Prince, pouvoir et peuple dans les commentaires de la Bible au Moyen Âge, Paris, Beauchesne, 1994.

${ }^{34}$ Passa cioè dai principi che regolano l'exemplum sinneddotico a quelli che vigono nell'exemplum metaforico. La distinzione tra forme esemplari sineddotiche (in cui la lezione viene estratta selezionando e generalizzando gli elementi della narrazione ad essa pertinenti) e forme metaforiche (dove l'insegnamento è invece illustrato mediante l'analogia) si deve a Claude Bremond, «Structure de l'exemplum chez Jacques de Vitry», in Letterature classiche e narratologia, Atti del Convegno Internazionale di Selva di Fasano [Brindisi] (6-8 ottobre 1980), Perugia, Istituto di Filologia Latina dell'Università di Perugia, 1981, pp. 27-50.

${ }^{35}$ In particolare da questo rispetto studia il commento del consejero Pablo A. Cavallero, «El conde Lucanor y el método exegético», in Thesaurus, 43 (1988), pp. 112-121.

${ }^{36}$ «L'interpretazione figurale stabilisce fra due fatti o persone un nesso in cui uno di essi non significa soltanto se stesso, ma significa anche l'altro, mentre l'altro comprende o adempie il primo. I due poli della figura sono separati nel tempo, ma si trovano entrambi nel tempo, come fatti o figure reali; essi sono contenuti entrambi $[\ldots]$ nella corrente che è la vita storica, mentre solo l'intelligenza, l' "intellectus spiritualis", è un atto spirituale; un atto spirituale che considerando ciascuno dei due poli ha per oggetto
} 
Testamento, intesi come figurae anticipatrici, preannunci profetici, di accadimenti che si adempiono nel Nuovo ${ }^{37}$. Qui al testo biblico, reale e storico, si sostituisce una fictio che, veicolo di una morale laica nella tradizione (definita da Reinaldo Ayerbe-Chaux ${ }^{38}$ «línea anecdótica») rappresentata dalla Disciplina, dai Castigos e dal Zifar, testi nei quali la prova degli amici, mezzi o interi che siano, riguarda esclusivamente i rapporti umani, viene ricondotta «nell'alveo della morale cristiana» ${ }^{39}$. Ma anche questa operazione è frutto di un incrocio, non privo per altro di qualche precedente, stavolta non all'interno dello stesso ramo (i materiali selezionati, combinati e fusi nel modo che si è visto, derivano tutti dalla «linea anecdótica») ma con un'altro ramo (la «línea alegórica» di Ayerbe-Chaux) della tradizione narrativa, pure di origine orientale e altrettanto rigoglioso, sull'amicizia e sull'importanza di testare gli amici. Si tratta del ramo rappresentato dall'esempio dei «tres amigos» tramandato in castigliano dal Barlaam e Josaphat (xIII secolo), adattamento cristiano della vicenda di Buddha da cui don Juan mutua, come si sa, la cornice entro cui racchiude le parti teoriche e didascaliche del suo Libro de los estados. Questa, in breve, la storia: ${ }^{40}$

\footnotetext{
il materiale dato o sperato dell'accadere passato, presente o futuro, non concetti o astrazioni; questi sono affatto secondari perché anche la promessa e l'adempimento sono fatti reali e storici che in parte sono accaduti nell'incarnazione del Verbo, in parte accadranno nel suo ritorno. È vero che nelle concezioni dell'adempimento finale intervengono anche elementi puramente spirituali, perché "il mio regno non è di questo mondo"; ma sarà pur sempre un regno reale, non una costruzione astratta e sovrasensibile; questo mondo perirà soltanto come "figura", non perirà la sua "natura" [...] e la carne risorgerà. L'interpretazione figurale pone dunque una cosa per l'altra in quanto l'una rappresenta e significa l'altra, e in questo senso essa fa parte delle forme allegoriche nell'accezione più larga. Ma essa è nettamente distinta dalla maggior parte delle altre forme allegoriche a noi note in virtù della pari storicità tanto della cosa significante quanto di quella significata» (Erich Auerbach, Figura [1944], trad. it. in Id., Studi su Dante, Milano, Feltrinelli, 1963, pp. 174-221, alle pp. 204-205); si veda anche Alastair J. Minnis, Medieval Theory of Authorship, London, Scolar Press, $1988^{2}$, s.v. prefiguration.

${ }^{37}$ Metodo che d'altronde don Juan mostra di conoscere allorché, nel Libro de la doctrina, connette la purificazione della circoncisione, praticata nella vecchia legge, con la purificazione del battesimo nella nuova legge, chiarendo che «en cuanto duró aquella ley cunplían aquel sacramento, por que entendades que todo lo que en aquella ley fue ordenado, que todo fue por figura desta sancta ley que agora avemos, devédeslo entender señaladamente en este sacramento del baptismo, ca entonce circuncidavan los omnes, et ya en esta paresce que era figura que de otra guisa avía de seer» (p. 267; il concetto compare anche nel Libro de los estados, I XLIII e II XXXI).

${ }^{38}$ «El conde Lucanor». Materia tradicional..., op. cit., p. 161.

${ }^{39}$ A. Ruffinatto, «Il mondo possibile...», art. cit., p. 221. «Pertanto, anche in questa circostanza, come altrove nello stesso $C L$ e in altre sue opere (principalmente il Libro de los estados), don Juan Manuel paga un debito di riconoscenza all'ordine da lui prediletto, quello dei domenicani, riproponendo in ambito profano i modelli della loro predicazione» (ibidem).

${ }^{40} \mathrm{Sia}$ il riassunto che le considerazioni che seguono tengono conto di tutte e tre le versioni dell'opera pervenuteci. Cito il testo dall'ed. a cura di John E. Keller e Robert W. Linker, Madrid, CSIC-Instituto Miguel de Cervantes, 1979.
} 
Un uomo ha tre amici. Ama il primo più del secondo e il secondo più del terzo, che ha sempre trascurato. Colpito da disgrazia e temendo il giudizio del re, chiede il loro aiuto. L'amico cui vuole molto bene nega il suo aiuto e gli dona delle povere vesti con cui coprirsi. Si rivolge allora al secondo, il quale gli risponde di non avere tempo da dedicargli, ma promette di accompagnarlo dal re. Vergognandosi per non averlo amato a sufficienza, si reca infine dal terzo, che proprio per quel poco di bene che ha ricevuto è disposto a presentarsi con lui dinanzi al re e a intercedere in suo favore.

Storia seguita, senza alcuna soluzione di continuità, dalla sua interpretazione metaforica per bocca dello stesso narratore, il saggio Barlaam:

El primero amigo por çierto es el aver de las rriquezas e el amor de los averes, por las quales cosas el omne se somete a muchos periglos e sufre muchas mesquinidades. Veniendo el postrimero dia de la muerte, non toma ninguna cosa de ellas, synon unos pañezuelos syn provecho que pertenesçen a la sepultura. El segundo es llamado la muger e los fijos e los cormanos e los otros amigos, por el talante de los quales llegandonos, non nos podemos partir, menospreçiando el alma e el cuerpo por amor dellos. Mas dellos non ha ningund provecho en la ora de la muerte sinon que van con el fasta el monimento; desende tornadose, catan por sus cuydados, non menos cobriendo la memoria de la olvidança que el cuerpo del sepulcro.

Mas el amigo terçero menospreçiado, e non gran familiar, mas aborresçido, es el choro de las obras derechureras; e conviene saber esperança e fe e caridat, la limosna, la humillad e el otro ayuntamiento de virtudes, el qual puede yr ante nos, quando salimos del cuerpo, e ponerse ante Dios por nos, e librarnos de las cosas fechas; este es el amigo gradesçible, e qual la nuestra buena obra toma en memoria e tornala con husura (Barlaam, ms. S, p. 389).

Una versione più succinta si deve a Jaques de Vitry (Sermones vulagres, § 120). Qui la prova di amicizia è innescata dalla condanna a morte di un servo da parte del suo signore:

Unde legimus quod quidam vir potens et magnus cuidam servo suo castrum custodiendum commisit in quo hostes domini recepit, propter quod dominum eum suspendi jussit. Cum que traheretur ad mortem rogavit quemdam amicum suum quem valde dilexerat ut ei in tanta necessitate subveniret ${ }^{41}$.

${ }^{41}$ The Exempla or Illustrative Stories from the Sermones vulgares of Jacques de Vitry, ed. a cura di Thomas F. Crane, London, D. Nutt, 1890, p. 55. 
Il terzo amico non si limita pertanto ad assicurare la propria intercessione, ma si dichiara disposto a salire in sua vece sulla forca:

Qui respondit: «Non immemor modici beneficii quod mihi fecisti; cum usura reddam tibi; ponam animam meam pro anima tua, vitam meam pro liberatione tua, et suspendar pro te».

Ancor più significativa risulta, per noi, la conseguente rielaborazione della parte commentativa. Gli amici diventano infatti quattro: l'ultimo resta irrelato con il racconto e rappresenta, sulla scia del Barlaam, le opere della misericordia, mentre il terzo, quello che offre in sacrificio la propria vita, viene identificato con Cristo, morto per la salvezza degli uomini:

Primus amicus possesiones terrene que in morte dant tantum panniculum ad sepeliendum et cito novos amicos inveniunt. Secundus amicus uxor et filii et consanguinei qui usque ad sepolcrum sequuntur et statim ad domum revertuntur. Tercius et vetus amicus est Christus qui pro liberatione nostra voluit in patibulo crucis suspendi, et insuper quartus amicus qui nos precedit viam preparando et pro nobis regem intercedendo, opera scilicet misericordie et alia bona que facimus ante mortem, ut nobis succurrant in necessitate.

Un quarto amico è presente, stavolta anche come attore diegetico, nella Scala Coeli di Jean Goby ( $\$ 60)$. Morto il padre, ricco cortigiano, un giovane ne eredita i beni, ma li dissipa in breve tempo con tre suoi compagni. Ridotto in miseria, commette un omicidio e viene condannato. In virtù del suo rango può scegliere tra la pena capitale e il pagamento di un'ammenda. Chiede allora aiuto ai tre presunti amici, le cui risposte ricalcano sostanzialmente quelle dei primi due interpellati nel Barlaam (offerta di un panno per coprirsi gli occhi durante l'esecuzione, impegno a scortarlo al patibolo, promessa di ritirare la scala dalla forca). Disperato, il giovane si sovviene di un buon uomo che per affetto verso i genitori lo aveva spesso rimproverato per i suoi comportamenti e lo manda a chiamare. Ascoltata la confessione delle colpe da lui commesse, il buon uomo gli consegna il denaro che lo salva dalla morte. Il racconto è accompagnato da una articolata moralizzazione, nella quale il quarto amico rappresenta Cristo:

Comes est Deum pater, comitatus sunt bona spiritualia, sacramenta ecclesie et opera misericordie. Filius est homo qui adherens peccatis homicida efficitur imaginis Dei; et ideo adjudicatus est morti, nesciens tempus, modum et statum. Quia vero omnia bona sua dissipavit cum tribus amicis, scilicet cum mundo, 
parentibus et dyabolo, ad istos recurrit in morte. Et primus, scilicet mundus, dat tantum sudarium auferens omnes honores, omnia bona temporalia, oblitus omnium laborum factorum propter eum. Secundus amicus, scilicet parentes, associant usque ad patibulum sepulture. Tercius amicus scilicet dyabolus, vertit scalam, id est spem a se promissam auferendo gloriam et dando damnationem eternam. Quartus qui est contemptus est Christus, qui est plenus benignitate et misericordia, accedit ad contritum existentem in carcere peccati, et sibi quinque vulnera tradit in redemptionem et mortis liberationem ${ }^{42}$.

Maggiore affinità con i racconti della linea aneddotica mostra la narrazione contenuta nelle Fabulae di Odo de Cheriton. Il giovane protagonista è sollecitato dal padre ad assicurarsi degli amici e, rispettivamente con il lavoro, i doni e l'omaggio, se ne procura tre. Il genitore gli suggerisce di metterli alla prova: dovrà fingere di essere stato accusato dal re del crimine di lesa maestà per verificarne le reazioni. I tre sedicenti amici rifiutano di soccorrerlo, minacciando il primo di privarlo di ogni suo avere, il secondo di farlo incarcerare e il terzo di condurlo al patibolo per impiccarlo. Il padre lo esorta allora a rivolgersi a un suo amico, il quale non esita ad assumere su di sé la responsabilità del delitto. Ed ecco la lettura "mistica" fornita da Odo, nella quale a fungere da figura Christi è naturalmente l'unico amico del padre (i falsi amici rappresentano invece il mondo, la carne e il demonio):

Mistice. Primus amicus est mundus, vel pecunia pro qua homo se totum consumit nocte et die, laborando et solicitando. Eccles.: Cuncti dies eius lab., etc., nec per noctem sinit dormire; set in morte, quando magnus rex vocat ad curiam suam vt respondeat vnusquisque pro transgressionibus suis, nichil sibi dimittit, set aliis que habet tribuens, mundus eum eicit, vt dicat talis illud, Jeremias, xx: Comedit me et deuorauit me rex Nabugodonosor; repleuit me temeritudine mea et eiciet me. Item Prouerbiorum quinto: Ne des alienis robur vel honorem tuum et amicos tuos crudeli. Secundus est caro et amici carnales, qui pastum et procuracionem large recipiunt, set vsque ad carcerem, id est sepulcrum, deducunt et in profundum proiciunt. Tertius est diabolus, qui vsque ad vltimum iudicium deducit et ibi federatum sibi suspendit. Set quartus est Christus solus, qui pro amicis suis mortem sustinuit, et solus verus amicus fuit. Tullius de Amicitia: Qui in prosperis et aduersis constantem stabilemque se in amicitia prostiterit, hunc maxime ex raro hominum genere iudicare debemus amicum, et generi diuino comparabitur ${ }^{43}$.

${ }^{42}$ La Scala Coeli de Jean Gobi, ed. a cura di Marie-Anne Polo de Beaulieu, Paris, Éditions du CNRS, 1991, p. 187.

${ }^{43}$ Léopold Hervieux, Les fabulistes latins depuis le siècle d'Auguste jusqu'à la fin du moyen âge, IV. Eudes de Cheriton et ses derivés, Paris, Librairie de Firmin-Didot, 1896, pp. 394-395. 
Un tipo misto è testimoniato infine dai Gesta romanorum (§ 129). La prima metà segue il percorso del Dimidio amico, con la confezione del sacco ingannatore (nella variante maiale) compresa:

Quidam rex habuit tantum unicum filium, quem multum dilexit; qui filius a patre licenciam accepit, ut mundum visitaret et amicos sibi acquireret. Qui per septem annos vagabat in mundo et post hec ad patrem rediit. Pater gaudenter eum recepit et ab eo quesivit, quot amicos acquisivisset. At filius: Tres; primum amicum plus, quam me ipsum diligo, secundum tantum sicut meipsum, et tercium parum aut nichil. Cui pater: Bonum est eos probare et temptare, antequam indigeas de eis. Porcum occide et in sacco pone et in domum amici, quem plus diligis quam te, perge de nocte et ei dic, quod a casu hominem occidisti; et si inventum fuerit corpus mecum, morte turpissima ero condempnatus; rogo modo te, sicut te semper plus, quam meipsum, dilexi, succurre michi in hac maxima necessitate! Quod et factum est ${ }^{44}$.

La seconda parte riprende invece lo schema che ormai ben conosciamo del racconto dei tre amici. Ampia e dettagliata anche in questo caso la lettura metaforica:

Moralizacio. Carissimi, rex ille est deus omnipotens; filius unicus est quilibet bonus christianus, qui per XII annos i. e. in toto tempore vite sue habet in mundo conversari et tres amicos querere. Primus est mundus, quem plus diligit quam seipsum. Probatur hoc; propter mundum homo ponit se in periculo mortis, modo in mari, modo in terra vitam sepe amittendo, ut temporalia bona possit habere; ergo plus diligit mundum quam seipsum. Et si eum tempore necessitatis probaveris, sine dubio tibi deficiet; immo de omnibus bonis tuis si tibi dederit duas ulnas vel tres de panno ad involvendum corpus tuum, multum est. Secundus amicus, quem tantum diligis sicut teipsum, est uxor tua et filii tui et filie; que bene ad sepulchrum in morte tecum plorando pergunt, et cum uxor ad domum redierit, infra paucos dies dolor recedit et alium incipit amare. Tercius amicus, pro quo parum fecisti, est Christus, pro cujus amore pauca bona sumus operati, immo multa mala, qui tempore mortis amicus est, si contriti et confessi fuerimus; immo pro nobis mortem in cruce sustinuit ${ }^{45}$.

Ma non mancano neppure esemplari che propongono un'interpretazione teologica anche per le due narrazioni proemiali della Disciplina clericalis. È il caso della Scala coeli, nella quale Pedro Alfonso è la fonte dichiarata. Varrà

${ }^{44}$ Gesta Romanorum, ed. a cura di Hermann Oesterley, Berlin, Weidmann, 1872, p. 483.

${ }^{45}$ Ibidem, pp. 483-484. 
la pena riportare entrambe le moralizzazioni. Ecco quella che segue la sintetica versione del racconto dell'amico intero $(\S 68)$ :

Mercator de Baldaco est Filius Dei, mercator de Egipto peccator, receptio est incarnatio; jocalia sunt virtutes; depauperatio, peccati commissio; homicidii confessio, desperatio divine misericordie, quam tollendo Christus morti se obtulit pro nobis ${ }^{46}$.

Ed ecco l'esposizione che accompagna l'altrettanto breve sunto della storia del mezzo amico (§ 69):

Pater est Deus, filius peccator cujus amici reputantur mundus, caro, demonia quibus confudimur continue, sed verus amicus est Christus qui sepelevit peccata nostra et remittit ${ }^{47}$.

Né va dimenticato che negli stessi Castigos, fin dalla loro redazione primitiva $(\alpha)$, l'esempio sull' amicizia a metà «se inclin $a$ » decisamente «hacia la tradición cristiana ${ }^{48}$; esso risulta infatti incorniciato da una serie di citazioni dal Nuovo e dal Vecchio Testamento che fungono da glossa, condizionandone ovviamente l'interpretazione:

Mío fijo, vno de los tesoros que el padre puede dexar al fijo que mucho ama e finca por su heredero mayor sí es en dexarle buenos amigos; mas todos los que el omne cuenta por amigos non son todos eguales en amistad nin en bondat, segund que dize Ihesu Christo en el Euangelio, ó dize: Muchos son los llamados e pocos los escogidos. [...] El que vieres que se te da por amigo a la ora de la cuyta e de la priesa e non cata por la su ganançia nin por la su pérdida en tal de te saluar a ti e a la tu fazienda e de fazer contra ti lo que deue, tal omne commo éste cuenta por amigo leal e verdadero e conplido. Dize Ihesu Christo en el Euangelio: Mayor amor non puede vn omne mostrar a otro que poner la su alma por él. E por grand amor que ouieron los santos e las santas con Dios pusieron los sus cuerpos a martirios e a muerte, e despreçiaron lo déste mundo por ganar el amor de Dios e la gloria e la honrra de los çielos que dura para sienpre. [...] Ca dize el rey Salamón: Todas las loores son acabadas a la çima en qual fin fazen. Otrosí dize Salamón: Tres cosas son que non dexan rastro en pos sí: La primera es el aue que buela en el ayre; la segunda la naue en el agua por ó pasa; la terçera la culebra sobre la piedra. Otrosí la buena amistad e derecha con amor verdadero sienpre dexa buen rastro en pos sí, así commo la mala dexa mal rastro e mala fama. [...] ¿Qué te diré más? El amor ayunta

${ }^{46}$ La Scala Coeli..., ed. cit., p. 191.

${ }^{47}$ Ibidem, p. 192.

${ }^{48}$ M. . J. Lacarra, «El “medio amigo”...», art. cit., p. 286. 
e afirma todos los bienes e el desamor mete todos los males. E por eso dixo el rey Salamón: Amor vençe todas las cosas del mundo. E Ihesu Christo dixo en el Euangelio: Guay del omne por quien se leuanta «el escándalo e〉 el desamor e la discordia e el mal. Por tu buena palabra puedes ganar vn amigo o por la tu palabra mala lo puedes perder. E por el tu buen fecho te ganarás con tu amigo o por el mal fecho te perderás con él (CDS pp. 256-57, 263-264).

Non a caso la versione $\beta$, che come si è visto fonde $\mathrm{i}$ due modelli della lealtà amicale, fa del mezzo amico il protagonista di un vero e proprio «acto evangélico»: alla provocazione del giovane, costretto dal padre a colpirlo, egli risponde porgendogli l'altra guancia («Avnque me des otra a tuerto e sin derecho nunca se descobriran las uerças del huerto»; cfr. Luca 6, 29), gesto che gli vale appunto l'attribuzione del titolo di «conplido e uerdadero», per il quale l'«único» possibile «parangón es Cristo» ${ }^{49}$.

È il momento di ritornare all'esposizione «spiritual» dell'esempio XLVIII, a partire dalla quale Juan Manuel rielabora, riorganizza e risemantizza i materiali narrativi (le «fonti») utilizzati ${ }^{50}$, attivando con maestria una serie di tecniche manipolatorie: amputazione delle parti secondarie e accessorie che potrebbero compromettere la coesione semantica e il vigore dottrinale dell'enxiemplo; focalizzazione e amplificazione degli elementi pertinenti all'ammaestramento che intende offrire e/o introduzione di componenti inediti ${ }^{51}$; fusione di temi, motivi, segmenti o intere sequenze riconducibili a racconti-fonte ${ }^{52}$ distinti e

${ }^{49}$ Ibidem, p. 286.

${ }^{50}$ «Presi nella fitta rete di implicazioni tra i livelli, i materiali narrativi del $C L$ provenienti da varie culture (da quella orientale a quella occidentale classica e cristiana) perdono in parte la loro potenzialità diegetica, si spogliano di ogni possibile ambiguità sul piano dell'interpretazione e si adeguano anche strutturalmente alle esigenze di una cornice che non è semplice pre-testo (come nei prodotti di importazione) ma è, invece, con-testo e inter-testo» (A. Ruffinatto, «Il mondo possibile...», art. cit., p. 208).

${ }^{51} \mathrm{Su}$ queste due figure dell'intertestualità (ellissi e amplificazione) utilizzate da don Juan ha attratto l'attenzione (rifacendosi a Laurent Jenny, «La stratégie de la forme», in Poétique, 27 [1976], pp. 257281), A. Ruffinatto, ibidem, p. 205. Una dettagliata analisi, sia pure limitata all'aspetto prettamente linguistico, delle tecniche di amplificatio e di brevitas adottate nel Conde Lucanor, si deve a Ermanno Caldera, «Retorica, narrativa e didattica nel Conde Lucanor», in Miscellanea di Studi Ispanici, 14 (19661967), pp. 5-120, alle pp. 35-45; più in generale si veda Barry Taylor, «Versiones largas y breves de textos castellanos medievales y áureos: la cuestión de la prioridad», in Text \& Manuscript in Medieval Spain, Papers from the King's College Colloquium, a cura di D. Hook, Exeter, Department of Spanish \& Spanish-American Studies, King's College London, 2000, pp. 79-102.

${ }^{52}$ Rifacendosi al concetto di "intertestualità', nelle premesse teoriche al loro contributo sul capolavoro boccacciano, Costanzo Di Girolamo e Charmane Lee, «Fonti», in Lessico critico decameroniano, a cura di R. Bragantini e P. M. Forni, Torino, Bollati Boringhieri, 1995, pp. 142-161, alle pp. 143-144, distinguono opportunamente tra «testo-fonte», allorché è possibile «individuare una derivazione diretta e lineare da un altro testo», e «racconto-fonte»: «È [...] difficile, nella discussione di un rapporto di fonte, stabilire quale versione di un testo l'autore che lo riusa abbia conosciuta, anche a causa della proliferazione di versioni dello stesso racconto (è superfluo ricordare l'auctoritas debole connessa alla narrazione breve medievale). Anche quando la cronologia è chiara, come nel caso di Boccaccio, rispetto alla 
indipendenti; istituzione di parallelismi tra la situazione prospettata dal conte e quella descritta nella narrazione, che dà origine a veri e propri giochi di specchi; opzione per una diegesi tutta condotta dall'esterno, sorvegliata e impersonale ${ }^{53}$, contrazione di dialoghi e descrizioni, e così via. In particolare, il commento estende la tipologia a tre (Barlaam e continuatori) o quattro figure (Sermones vulgares, Scala coeli) della «linea allegorica» della prova di amicizia a sei figure, istituendo le seguenti relazioni tra il livello letterale e il livello metaforico (CL pp. 197-200):

a) giovane che testa la genuinità degli amici = a') uomini tutti nel momento del trapasso

fijo [del] omne bueno [que] fue provar sus todos los omnes en este mundo tienen que han amigos amigos, et cuando viene la muerte, hanlos de provar en aquella quexa

b) presunti amici che gli negano ogni aiuto = b') clero secolare

todos le dixieron [...] que non se atreverían a Et van a los seglares, et dízenles que assaz han le ayudar que fazer en sí

c) presunti amici che promettono preghiere

$\left.=\mathrm{c}^{\prime}\right)$ clero regolare

algunos le dixieron [...] que yrían rogar por él van a los religiosos, et dízenles que rogarán a Dios por ellos

d) presunti amici che promettono onoranze funebri $=$ d') familiari

et otros le dixieron que cuando le levassen a la muerte, que non lo desenpararían fasta que oviessen conplido en él la justicia et quel farían onra al su enterramiento

e) padre che consiglia il figlio (vedi anche i) = e') Dio che indirizza verso la salvezza (vedi anche i')

Desque el mancebo ovo provado assí todos sus amigos et non falló cobro en ninguno, tornóse para su padre et díxol todo lo quel acaesciera van a la mujer et a los fijos, et dízenles que yrán con ellos fasta la fuessa et que les farán onra a su enterramiento
Et desque non fallan en ellos ningún cobro para escapar de la muerte, assí commo tornó el fijo depués que non falló cobro en ninguno daquellos que cuydava que eran sus amigos, tórnanse a Dios, que es su padre

tradizione letteraria classica, mediolatina e gallo-romanza, non si può mai essere sicuri della forma della fonte utilizzata, e delle modalità con cui l'autore ne è venuto in contatto: se la ha ascoltata o la ha letta; $\mathrm{e}$, se la ha letta, se aveva un testo davanti quando scriveva o lo ricordava a memoria. In quest'ultimo caso potremmo parlare di un racconto-fonte, senza porci ulteriori problemi per risalire all'eventuale testofonte che è all'origine della novella».

${ }^{53}$ Fatta eccezione per i casi in cui il condizionamento del livello interpretativo sui racconti incorniciati si esercita meno intensamente, per cui Juan Manuel può più liberamente esprimere le proprie potenzialità di narratore, nella maggioranza degli esempi del Conde Lucanor i sommari (per usare la terminologia di Gérard Genette, Figure III. Discorso del racconto [1972], trad. it., Torino, Einaudi, 1976, pp. 144-148 e 158-161) prevalgono nettamente sulle scene. 
f) mezzo amico

Estonce le dixo que él non avía más de un amigo et medio, et que los fuesse provar.

El mancebo fue provar al que su padre tenía por medio amigo.

g) aiuto del mezzo amico

Cuando el medio amigo de su padre aquello vio, díxol que con él non avía amor nin afazimiento por que se deviesse tanto aventurar, mas que por el amor que avía con su padre que gelo encubriría

h) offesa al mezzo amico

El padre le mandó [...] quel diesse una puñada en el rostro, la mayor que pudiesse. El mancebo fizo lo quel mandó su padre. Et cuando gela dio, catól el omne bueno et díxol [que] non descubriria las coles del huerto
= f') $i$ santi e, in primo luogo, la Vergine, intermediaria per eccellenza tra l'uomo e Dio

et Dios dízeles que prueben a los sanctos, que son medios amigos. Et ellos fázenlo

$\left.=\mathrm{g}^{\prime}\right)$ intercessione dei santi

Et tan grand es la bondat de los sanctos et sobre todos de Sancta María, que non dexan de rogar a Dios por los pecadores

= h') pene di Maria nel mettere al mondo e nell'allevare suo figlio e tormenti patiti dai santi, in nome e a imitazione di Cristo, per "coprire" le colpe dei peccatori

Et sancta María muéstrale cómmo fue su madre et cuánto trabajo tomó en lo tener et en lo criar, et los sanctos muéstranle las lazerias et las penas et los tormentos et las passiones que recebieron por Él. Et todo esto fazen por encobrir los yerros de los pecadores. Et aunque ayan recebido muchos enojos dellos, non le descubren, assí commo non descubrió el medio amigo la puñada quel dio el fijo de su amigo

\section{i) amico intero che immola il figlio (vedi anche e) = i') lo stesso Dio, che per amore verso l'umanità sacrifica il suo unico figlio (vedi anche e')}

Et desque llegó a casa del amigo de su padre et le contó todo lo que li avía contescido, dixo el omne bueno, amigo de su padre, que él le guardaría de muerte et de daño

\section{1) figlio dell'amico intero}

El mancebo fue jubgado que lo matassen. Et el amigo de su padre avía fecho cuanto pudiera por lo escapar. Desque vio que en ninguna manera non lo pudiera librar de muerte, dixo a los alcaldes que non quería levar pecado de aquel mancebo, que sopiessen que aquel mancebo non matara el omne, mas que lo matara un su fijo solo que él avía. Et fizo al fijo que lo cognosciesse, et el fijo otorgólo, et matáronlo. Et escapó de la muerte el fijo del omne bueno que era amigo de su padre
Et desque el pecador vee spiritualmente que por todas estas cosas non puede escapar de la muerte del alma, tórnasse a Dios, assí commo tornó el fijo al padre después que non falló quien lo pudiesse escapar de la muerte. Et nuestro señor Dios, assí commo padre et amigo verdadero, acordándose del amor que ha al omne, que es su criatura, fizo commo el buen amigo

\section{= 1') Gesù Cristo}

ca envió al su fijo Jhesu Christo que moriesse, non oviendo ninguna culpa et seyendo sin pecado, por desfazer las culpas et los pecados que los omnes merescían. Et Jhesu Christo, commo buen fijo, fue obediente a su padre. Et seyendo verdadero Dios et verdadero omne, quiso recebir, et recebió, muerte, et redimió a los pecadores por la su sangre 
Si comprendono a questo punto le ragioni del «collage intertestuale» realizzato da Juan Manuel. L'intreccio del De dimidio amico ben si prestava a stabilire una serie di equivalenze e ad accogliere gli innesti necessari per aggiungerne altre. Era sufficiente riprendere la tripartizione proposta dal Barlaam (che offriva oltretutto un utile modello interpretativo), e applicarla agli indifferenziati amici consultati dal giovane della Disciplina clericalis, rendendo anche il terzo tipo, in origine leale e sincero, parzialmente negativo, non idoneo a dimostrare la vera amicizia, e interpolare la sequenza della prova supplementare riservata al mezzo amico, rintracciabile nel ramo $\beta$ dei Castigos. In questo modo risultava possibile connettere: il figlio cui il padre consiglia di assicurarsi degli amici, il quale si finge prima e si ritrova poi in pericolo di vita, accusato di un delitto che non ha commesso (a), con gli uomini tutti, condannati alla morte dell'anima perché segnati, al di là della loro colpevolezza individuale, dal marchio atavico della Caduta ${ }^{54}$, che li ha resi vulnerabili al peccato ${ }^{55}$, ai quali Dio (vedi $e$ ) raccomanda di garantirsi un sicuro soccorso $\left(a^{\prime}\right)$; i presunti amici che non osano aiutarlo $(b, c, d)$, con quanti, clero secolare, clero regolare e familiari, possono al più pregare per l'anima dell'uomo e accompagnarlo alla sepoltura $\left(b^{\prime}, c^{\prime}, d^{\prime}\right)$; il padre dal quale il figlio, non avendo trovato aiuto, ritorna, ricevendone un secondo consiglio $(e$, ma vedi anche $i$ ), con Dio ( $e^{\prime}$, equivalente ad $i$ '); il mezzo amico $(f)$ che aiuta il giovane in virtù dell'amicizia che lo lega al padre $(g)$, con i santi e in primis la Vergine $\left(f^{\prime}\right)$, i quali per amore verso Dio, pur non avendo la facoltà di redimerne le colpe, intercedono a favore del peccatore $\left(g^{\prime}\right)$, perdonandogli gli «enojos» sofferti a causa sua $\left(h, h^{\prime}\right)^{56}$. Restavano irrelati gli ultimi due, fondamentali,

${ }^{54} \mathrm{Il}$ «peccato è originale non solo perché è all'origine della vita di ogni uomo, che nasce peccatore prima ancora di aver commesso alcun peccato. Il padre riconosciuto di questa teoria è sant'Agostino che, leggendo le pagine della Genesi alla luce del monito paolino "attraverso un solo uomo il peccato entrò nel mondo" (Lettera ai Romani, 5.12), afferma, in polemica con le posizioni dei pelagiani, la natura propagativa e non imitativa del peccato originale. Inoltre, secondo Agostino, trasmissione del peccato originale non significa solo trasmissione delle pene, come altri prima di lui avevano già sostenuto, ma anche trasmissione della colpa. La solidarietà della natura umana con la persona di Adamo, che comprende in sé tutta l'umanità in virtù della sua potenzialità generativa, fa sì che tutti gli uomini partecipino con lui al suo peccato, condividano la sua volontà di compiere quell'atto sciagurato e per questo ne condividano non solo la pena ma anche la colpa» (Carla Casagrande e Silvana Vecchio, «Peccato», in Dizionario dell'Occidente medievale. Temi e percorsi [1999], a cura di J. Le Goff e J.-C. Schmitt, trad. it., 2 voll., Torino, Einaudi, 2004, vol. II, pp. 871-884, a p. 873).

${ }^{55}$ «Spezzata con il peccato la perfezione e l'armonia del rapporto originario, anima e corpo convivono nell'individuo in uno stato di continua tensione che genera a sua volta peccato; da un lato una carne concupiscente, fonte di impulsi difficilmente controllabili, dall'altro uno spirito indebolito, sconvolto dalle passioni, incapace da solo di governare il corpo in cui abita e frenato nel suo desiderio di volgersi al bene» (ibidem, p. 872).

${ }^{56}$ Come osserva G. Séres, El Conde Lucanor, ed. cit., p. 407, «estas instancias citadas (la familia, los santos, etc.), además de representar "espiritualmente" al 'medio amigo', también representan al 'mediohombre', o sea, al que no es impulsado -al decir de Santo Tomás- por el motus intellectivae partis, sino al que se limita a encubrir yerros; al que no guarda las dos vidas activa et contemplativa». 
elementi ( $i$, equivalente ad $e$, ed $l$ ). A ciò pone rimedio la parziale combinazione con il secondo racconto di Pedro Alfonso. L'unificazione, con l'attribuzione della qualifica di amico intero ad un amico del genitore protagonista della prima parte, consente di conservare fino al termine il rapporto padre-figlio, proprio del racconto del De dimidio amico, ma assente in quello del De integro amico, indispensabile perché fosse poi possibile, previo il taglio della sequenza conclusiva del secondo intertesto (quella in cui il vero colpevole, colto dal rimorso, confessa pubblicamente la sua colpa e scagiona i due amici mercanti, entrambi condannati a morte), interpretare ${ }^{57}$ il personaggio del padre (più esattamente i due padri, associati, a formare con il giovane immolato una Trinità) come figura di Dio ( $e$ ', $\left.i^{\prime}\right)$, quello del figlio sacrificato come figura di Cristo $\left(l^{\prime}\right)$, il quale, proprio perché vero Dio e vero uomo, ma senza macchia originale («non oviendo ninguna culpa et seyendo sin pecado», $C L$ p. 200 ), con la propria morte ha reso possibile il riscatto dell'umanità dal peccato e dalla sua schiavitù, e il gesto di amicizia estrema e dal punto di vista terreno inaccettabile, come atto di amore infinito e umiltà suprema (da Dio farsi uomo e patire la morte) e perciò divino ${ }^{58}$.

Recibido: $25 / 04 / 2015$

Aceptado: 2/06/2015

${ }^{57} \mathrm{O}$ meglio, giuste le osservazioni di Ruffinatto, «Il mondo possibile...», art. cit., pp. 205 e 208, circa l'azione strutturante del livello interpretativo sul livello narrativo, è la lettura allegorica che presiede alla narrazione e la condiziona, dettando la trasformazione.

${ }^{58}$ Una suggestiva interpretazione dell'esempio è stata recentemente proposta da Paolo Cherchi, «I falsi amici e i veri amici (Conde Lucanor, I XLVIII)», in Medioevo Romanzo, 27 (2003), pp. 470-481. Constatato che nel racconto chi manifesta amicizia commette in realtà una gravissima ingiustizia (fornisce aiuto a un presunto assassino e addossa la colpa di un omicidio a un innocente), mentre quanti non accordano il proprio soccorso al protagonista, benché pecchino di compassione, si comportano giustamente, lo studioso osserva che a risolvere questa contraddizione «non può essere che il Dio cristiano, il quale nella sua paradossalità può essere amico anche del criminale, non perché se ne faccia complice ma perché nella sua infinita bontà lo perdona e lo redime col proprio sacrificio, lavandone col proprio sangue (quello del figlio, anche Lui vero Dio) la macchia del peccato e aprendogli in tal modo la via al cielo. Questa combinazione paradossale è prerogativa esclusiva della divinità, mentre gli uomini, in una situazione estrema come quella del racconto, possono attenersi soltanto ad uno dei due corni del dilemma o del paradosso» (p. 476); «Dio risponde con amicizia ad una estrema ingiustizia, ma questa ingiustizia risulta essere un autosacrificio in quanto lava l'offesa del peccatore con il proprio sangue, e non importa se Cristo è suo figlio perché questi è Dio stesso se pure in una persona distinta; e il sacrificio di un innocente, che potrebbe sembrare estrema ingiustizia, è in realtà il solo modo possibile con cui Dio può avere la satisfactio richiesta dalla giustizia, satisfactio che egli solo può rendere a se stesso. In tal modo un'estrema ingiustizia diventa paradossalmente la prova suprema di giustizia. A motivarla c'è l'amore per l'uomo, la suprema bontà di Dio» (p. 478). Sulla falsariga di S. Battaglia, «Dall'esempio...», art. cit., p. 503, tratto a sua volta in inganno da una erronea lezione dell'ed. Gayangos utilizzata, Cherchi non avverte tuttavia la presenza di un secondo personaggio, distinto dal mezzo amico, deputato a incarnare il modello comportamentale dell'amico intero, il che lo induce a denunciare una serie di incongruenze (doppia corrispondenza del mezzo amico prima con i santi e poi con Dio, duplice intervento del mezzo amico vs unico intervento di Dio a beneficio dell'uomo, ecc.), e lo costringe inevitabilmente, perché i conti tornino, a forzare i termini del rapporto tra lettera della narrazione e significato metaforico, laddove le equivalenze sono in verità puntualissime (l'unica dissimetria risiede nel fatto che a Dio rimandano non uno ma due diversi attori del cuento: il padre del giovane che mette alla prova gli amici e il padre dell'innocente sacrificato in sua vece). 


\section{«ET NUESTRO SEÑOR DIOS [...] FIZO COMMO EL BUEN AMIGO»: L'ESEMPIO XLVIII DEL CONDE LUCANOR E I SUOI PARALLELI (UNA RILETTURA)}

RIASSUNTO: Il nucleo narrativo dell'esempio XLVIII del Conde Lucanor, dedicato al tema dell'amicizia, è il frutto di un complesso montaggio intertestuale. Esso si ricollega al primo racconto della Disciplina clericalis (De dimidio amico) e alle sue rielaborazioni (le versioni tramandate dai Castigos y documentos del rey don Sancho e dal Libro del caballero Zifar), ma vi risultano integrate anche alcune componenti diegetiche costitutive del secondo, complementare racconto offerto da Pedro Alfonso (De integro amico), funzionali alla lettura tipologica che don Juan Manuel, per bocca di Patronio, ne proporrà in sede di commento. Anche questa operazione è tuttavia il risultato di un incrocio, stavolta con un altro ramo, pure di origine orientale, della tradizione narrativa sulla fede amicale, rappresentato dall'esempio dei «tres amigos» tramandato in castigliano dal Barlaam e Josaphat, che, insieme a una serie di riprese dei tre tipi di racconto nella letteratura esemplare mediolatina, offriva un modello interpretativo in chiave allegorico-cristiana del motivo della «prova degli amici».

PAROle ChiAve: Conde Lucanor. «Prova degli amici». Intertestualità. Interpretazione figurale.

«ET NUESTRO SEÑOR DiOS [...] Fizo COMMO EL BUEN AMIGO»:

The XLVIII EXemplary TAle of Count LUCANOR AND ITS EQUiVAlEnTs (A RE-REAding)

ABSTRACT: The narrative nucleus of the XLVIII Exemplary Tale of Count Lucanor, which is dedicated to friendship, is the result of a complex intertextual montage. It may be linked to the first short story of the Disciplina clericalis (De dimidio amico) and its re-elaborated versions (i.e. the versions which were handed down by the Castigos y documentos del rey don Sancho and the Libro del caballero Zifar). Yet it was also integrated with some diegetic components from the second complementary short story by Pedro Alfonso (De integro amico), which was also functional to the typological reading proposed by Juan Manuel through Patronio in the comments. This latter expedient may be regarded as a result of another encounter with the narrative tradition related to friendly faith represented by the example of the «tres amigos». The example was handed down in Castilian in the Barlaam e Josaphat, which together with a series of rewritings of the three types of story in Medieval Latin exemplary literature offered a Christian allegorical interpretative model of the «proof of friendship» topos.

KeYwords: Conde Lucanor. «Proof of friendship». Intertextuality. Figurative interpretation. 